\title{
AVALIAÇÃO DA CAVIDADE E HIGIENE ORAL DE IDOSAS RESIDENTES EM UMA INSTITUIÇÃO DE LONGA PERMANÊNCIA
}

Clóris Regina Blanski Grden¹, Luciane Patrícia Andreani Cabral², Pollyanna Kássia de Oliveira Borges³, Camila Soeiro de Sousa do Nascimento ${ }^{4}$, Lídia Dalgallo Zarpellon ${ }^{5}$, Carla Luiza da Silva ${ }^{6}$

RESUMO: Pesquisa quantitativa descritiva com objetivo de avaliar a cavidade e a higiene oral de idosas residentes em uma Instituição de Longa Permanência para Idosos, no município de Ponta Grossa-Paraná, em 2011. Os resultados apontam faixa etária predominante entre $71-75$ anos $(n=13 ; 33 \%)$, solteiras $(n=29 ; 72 \%)$ e não alfabetizadas $(n=31 ; 77 \%)$. Quanto à avaliação, $55 \%$ das idosas utilizam prótese dentária, $75 \%$ são edentadas e destas, $60 \%$ apresentaram periodontite; referente à higiene oral, $73 \%$ apresentavam condição ruim. Conclui-se que, apesar dos avanços tecnológicos, estudos referentes aos problemas bucais dos idosos são escassos, tornando necessária a elaboração de programas preventivos e educativos para que adultos e idosos possam planejar sua velhice com condições de saúde bucal mais satisfatória.

DESCRITORES: Higiene bucal; Idoso; Assistência odontológica para idosos.

\section{EVALUATION OF CAVITIES AND ORAL HYGIENE IN ELDERLY FEMALE RESIDENTS IN A LONG-TERM CARE FACILITY}

\begin{abstract}
Quantitative descriptive research, aiming to evaluate cavities and oral hygiene among elderly residents in a Long-Term Care Facility for the Elderly, in the municipality of Ponta Grossa in the state of Paraná, in 2011. The results indicate predominance of: age range between $71-75$ years old $(n=13 ; 33 \%)$, single $(n=29 ; 72 \%)$ and illiterate $(n=31 ; 77 \%)$. Regarding the evaluation, $55 \%$ of the elderly use dentures, $75 \%$ have few teeth, and of these, $60 \%$ have periodontitis; referent to oral hygiene, $73 \%$ have bad conditions. It is concluded that in spite of technological advances, studies referring to the oral problems among the elderly are few, making it necessary to elaborate preventive, educational programs so that adults and the elderly may plan their old age with more satisfactory oral health conditions.
\end{abstract}

DESCRIPTORS: Oral hygiene; Elderly; Dental assistance for the elderly.

\section{EVALUACIÓN DE LA CAVIDAD E HIGIENE BUCAL DE ANCIANAS QUE VIVEN EN UNA INSTITUCIÓN DE LARGA PERMANENCIA}

RESUMEN: Investigación cuantitativa descriptiva hecha con el objetivo de evaluar la cavidad y la higiene bucal de ancianas que viven en una Institución de Larga Permanencia para Ancianos, en el municipio de Ponta Grossa, Paraná, en 2011. Los resultados apuntan franja etaria predominante entre $71-75$ años $(n=13 ; 33 \%)$, solteras $(n=29 ; 72 \%)$ y no alfabetizadas ( $n=31 ; 77 \%)$. Acerca de la evaluación, $55 \%$ de las ancianas utilizan prótesis dentaria, 75\% presentan dientes y, de estas, $60 \%$ presentaron enfermedad en periodonto. Acerca de la higiene oral, $73 \%$ presentaban malas condiciones. Se concluye que, a pesar de los avances tecnológicos, estudios referentes a los problemas bucales de los ancianos son escasos, siendo necesaria la creación de programas preventivos y educativos para que adultos y ancianos puedan planear su vejez con condiciones de salud bucal más satisfactorias. DESCRIPTORES: Higiene bucal; Anciano; Asistencia odontológica para ancianos.

\footnotetext{
${ }^{1}$ Enfermeira. Mestre em Enfermagem. Doutoranda pelo Programa de Pós-Graduação em Enfermagem da Universidade Federal do Paraná. Professora do Departamento de Enfermagem e Saúde Pública da Universidade Estadual de Ponta Grossa - UEPG.

${ }^{2}$ Enfermeira. Mestranda em Tecnologia e Saúde pela Pontifícia Universidade Católica do Paraná- PUC PR. Professora do Departamento de Enfermagem e Saúde Pública da UEPG.

${ }^{3}$ Dentista. Doutora em Saúde Coletiva. Professora do Departamento de Enfermagem e Saúde Pública da UEPG.

${ }^{4}$ Enfermeira.

${ }^{5}$ Enfermeira. Mestre em Educação. Professora do Departamento de Enfermagem e Saúde Pública da UEPG.

${ }^{6}$ Enfermeira. Mestranda em Tecnologia em Saúde pela PUC PR. Bolsista CAPES. Professora do Departamento de Enfermagem e Saúde Pública da UEPG.
} 


\section{INTRODUÇÃO}

Atualmente, chegar à velhice é uma realidade mesmo nos países mais pobres. Ainda que a melhora substancial dos parâmetros de saúde das populações observada no século XX esteja longe de se distribuir de forma equitativa nos diferentes países e contextos socioeconômicos, envelhecer não é mais privilégio de poucos $^{(1)}$. O aumento da expectativa de vida e a diminuição das taxas de natalidade ocasionaram um aumento significativo no número de idosos no Brasil. No entanto, em sua maioria, o indivíduo atinge idade avançada com vários problemas de saúde, exigindo que outra pessoa, familiar ou não, assuma o papel de assisti$-1 \mathrm{o}^{(2)}$. Nesse sentido, o cuidador torna-se responsável por oferecer ajuda para suprir a incapacidade funcional, temporária, ou definitiva, incluindo ações que visam auxiliar o idoso, impedido física ou mentalmente a desempenhar tarefas práticas de atividades cotidianas e de autocuidado ${ }^{(3)}$.

Dentre as atividades diárias prejudicadas com a passagem dos anos está o cuidado com a higienização oral, o que acarreta em aumento da incidência de doenças bucais e sistêmicas.

A saúde bucal nos idosos mostra-se como um fator indispensável para o envelhecimento saudável e uma boa qualidade de vida, entretanto, as condições desiguais em que as pessoas vivem e trabalham são refletidas nitidamente na saúde da boca, uma vez que idosos expostos a situações de vulnerabilidade social estão mais sujeitos à interferência direta dos determinantes sociais no processo saúde-doença ${ }^{(4: 2976) \text {. }}$

Concernente à doença periodontal, é uma patologia que ocorre com frequência em idosos dentados mais vulneráveis e tem como agente causador a placa bacteriana que se acumula sobre as superfícies do esmalte dentário e no sulco gengival ${ }^{(5)}$. Desta forma, a periodontite é uma patologia oral de grande importância e é considerada a sexta complicação clássica do diabetes ${ }^{(6)}$. A boca, por não ser um órgão isolado do corpo humano, deve ser vista como parte integrante deste. Portanto, a saúde oral deve estar inserida no contexto da saúde geral e sistêmica e cabe aos responsáveis pelo cuidado ao indivíduo com alto grau de dependência mantê-la ${ }^{(7)}$.

Atualmente, a responsabilidade de assistir os idosos em suas atividades básicas de vida diária com maior frequência é de terceiros, pois, em muitos casos as famílias não dispõem de tempo para prestar os cui- dados necessários. Desta forma, a procura pela assistência em casas de repouso ou Instituições de Longa Permanência para Idosos (ILPI) torna-se uma opção. Estudos realizados nessas instituições revelam que o cuidado com a saúde bucal aos residentes não tem sido contemplado $^{(8-10)}$, situação que agrava-se nos casos em que os idosos apresentam algum grau de dependência ou autonomia comprometida. A motivação para este estudo ocorreu por meio da verificação de uma rotina inadequada de higiene oral em idosas dependentes e parcialmente dependentes para esta ação, e a preocupação com os agravos bucais e sistêmicos que podem ocorrer devido à falta de entendimento da importância deste cuidado.

Têm-se observado nas instituições, em geral, a ausência de protocolos de procedimentos, falta de atenção especializada e ausência de programas de orientação e capacitação dos cuidadores profissionais ou leigos ${ }^{(11)}$, o que pode ser justificado pela ausência, no Brasil, de normas específicas referentes ao cuidado à saúde bucal em instituições. Considera-se que a saúde bucal faz parte do cuidado do cliente como ser integral, sendo importante ressaltar que a realização regular da higienização oral pode prevenir patologias de origem periodontal. Portanto, há necessidade de adaptar e implantar protocolos com medidas sistematizadas de higiene bucal a serem adotadas nas instituições, bem como a capacitação dos cuidadores nessa atividade, a fim de manter a saúde bucal entre os idosos institucionalizadas $^{(12)}$.

Diante do exposto, o objetivo deste trabalho foi avaliar a cavidade e higiene oral de idosas residentes em uma instituição de longa permanência para idosos.

\section{MÉTODO}

Trata-se de um estudo quantitativo descritivo, derivado do projeto intitulado "A higiene oral no idoso: percepção da equipe de enfermagem em uma ILPI".

A coleta de dados ocorreu no período de 15 a 30 de agosto de 2011 em uma ILPI, localizada na cidade de Ponta Grossa, Paraná. A população compreendeu 40 idosas residentes na instituição. Foram estabelecidos os seguintes critérios para inclusão dos longevos no estudo: ser idoso (60 anos ou mais), sexo feminino, residir na ILPI, aceitar participar do estudo ou autorização da família, apresentar nível de cognição que possibilitasse a participação, identificado por meio dos pontos de corte do Mini Exame do Estado Mental (MEEM) ${ }^{(13)}$, e assinar o Termo de Consentimento Livre e Esclarecido (TCLE). 
A abordagem dos participantes ocorreu nas dependências da casa asilar, nos quartos e na sala de consulta de enfermagem, tendo como primeira etapa do estudo a triagem para a função cognitiva dos idosos longevos (screening cognitivo) por meio do MEEM. Foram utilizados os pontos de corte de 13 pontos para idosas analfabetas, 18 pontos para aquelas com escolaridade baixa e média e 26 pontos para escolaridade alta ${ }^{(13)}$.

Para as idosas que apresentaram dificuldades para se comunicar verbalmente, embora atingissem os pontos de corte, foi convidado a participar, nessa etapa, o cuidador familiar. Para esse cuidador, elencaram-se os seguintes critérios de inclusão: ter idade igual ou superior a 18 anos; ser familiar que auxilia no cuidado à idosa institucionalizada e assinar o TCLE.

Na sequência, avaliou-se a cavidade oral e o estado de higiene bucal das idosas, com base no instrumento de avaliação da $\mathrm{OMS}^{(14)}$, adaptado para a realidade da pesquisa. Nesta etapa, foi necessária a utilização de um evidenciador de placa bacteriana à base de eritrosina, flúor 1.100 PPM e sorbitol (açúcar não cariogênico). Este método é indicado como evidenciador de placa bacteriana para auxiliar no controle da higiene bucal, uma vez que marca a placa bacteriana na cor rosa ${ }^{(15)}$.

As variáveis coletadas foram dados sociodemográficos, uso de prótese, número de dentes, necessidades de extração ou substituição da prótese, dentes com cárie, perdidos ou restaurados, avaliação da higiene oral classificada em boa, regular ou ruim. O exame físico da cavidade oral foi realizado por meio de roteiro de avaliação elaborado pelos próprios autores, com as seguintes informações: coloração, textura, hidratação, presença de edema ou sangramento, lesões em lábios, mucosa, gengiva, língua, palato duro e mole.

Após a coleta de dados, foi realizada análise quantitativa simples, sendo os dados organizados e armazenados no banco de dados do programa Microsoft Office Excel® 2007, para posterior tabulação gerando estatísticas percentuais da amostra. Os dados foram organizados em gráficos e tabelas, com o intuito de demonstrar como se apresenta a cavidade e higiene oral das residentes.

O estudo foi consentido pelo diretor da instituição e aprovado pelo Comitê de Ética em Pesquisa da Universidade Estadual de Ponta Grossa, através do protocolo n. 16304/10. Foram observados os preceitos éticos exigidos pela Resolução 196/96 garantindo assim a desistência do estudo por parte das idosas e membros da instituição a qualquer momento da pesquisa.

\section{RESULTADOS}

A faixa etária predominante foi de $33 \%(\mathrm{n}=13)$ entre 71-75 anos; e a maioria era solteira, representando $72 \%$ $(\mathrm{n}=29)$, não alfabetizadas $(77 \%, \mathrm{n}=31)$ e a totalidade era de religião católica (Tabela 1).

Tabela 1- Caracterização sociodemográfica de idosas em uma ILPI. Ponta Grossa, 2011

\begin{tabular}{lcc}
\hline Faixa etária & $\mathbf{n}$ & $\mathbf{\%}$ \\
$60-64$ anos & 11 & 27 \\
$65-70$ anos & 04 & 10 \\
$71-75$ anos & 13 & 33 \\
$76-80$ anos & 04 & 10 \\
Acima de 80 anos & 08 & 20 \\
Estado civil & & \\
Casada & 01 & 03 \\
Viúva & 10 & 25 \\
Convivente & - & - \\
Solteira & 29 & 72 \\
Escolaridade & & \\
$1^{\circ}$ grau incompleto & 02 & 05 \\
$1^{\circ}$ grau completo & 05 & 13 \\
$2^{\circ}$ grau completo & 02 & 05 \\
Não alfabetizado & 31 & 77 \\
Religião & & \\
Católica & 40 & 100 \\
Evangélica & - & - \\
Outras & - & - \\
\hline
\end{tabular}

A segunda etapa da pesquisa compreendeu a avaliação da cavidade e higiene oral das idosas, representado na tabela 2 , e demonstrou que $55 \%(\mathrm{n}=22)$ apresentavam prótese dentária enquanto as demais, não.

Quanto à necessidade de uso, 18 idosas que não possuíam prótese deveriam estar utilizando, pois apresentavam lesões em mucosas e gengivas causadas durante a alimentação. Das 22 residentes que possuíam prótese, $64 \%(\mathrm{n}=14)$ necessitavam novas próteses pois, as utilizadas apresentavam-se desgastadas, quebradas, em péssimas condições de uso, o que pode ocasionar lesão na cavidade bucal.

Em relação ao número de dentes, das 40 idosas que participaram do estudo $75 \%(n=30)$ não possuíam nenhum dente. Entre as 10 participantes dentadas e de acordo com a tabela 2 a seguir, $70 \%(\mathrm{n}=7)$ apresentavam cárie e $70 \%(\mathrm{n}=7)$ possuíam dentes obturados; $60 \%(\mathrm{n}=6)$ estavam com periodontite, e todas necessitavam de alguma extração dentária.

Referente à higiene oral, $3 \%(\mathrm{n}=1)$ apresentavam boa 
Tabela 2- Caracterização da cavidade oral de idosas. Ponta Grossa, 2011

\begin{tabular}{lcc}
\hline Uso de prótese dentária & $\mathbf{n}$ & $\mathbf{\%}$ \\
Sim & 22 & 55 \\
Não & 18 & 45 \\
Necessidade de substituição & 14 & 64 \\
Presença de dentes & & \\
Edentadas & 30 & 75 \\
Dentadas & 10 & 25 \\
Cáries & 7 & 70 \\
Obturações & 7 & 70 \\
Periodontite & 6 & 60 \\
Necessidade de extração & 10 & 100 \\
\hline
\end{tabular}

condição, $25 \%(n=10)$ regular e $73 \%(n=29)$ ruim. O exame físico da cavidade oral, conforme a tabela 3 , revelou que $93 \%(n=37)$ das idosas possíam coloração de lábios normal; $97 \%(n=39)$ estavam dentro da faixa de normalidade em relação a edema labial; lábios hidratados (88\%; $\mathrm{n}=35)$; com lesões observadas em 33\%(n=13) das participantes. Em relação à mucosa 100 todas possuíam coloração, textura e hidratação normal, com integridade em $63 \%(n=25)$. A coloração normal da gengiva estava presente em todas as idosas e presença de lesão em tecido gengival foi verificada em $48 \%(\mathrm{n}=19)$ das participantes; $52 \%(\mathrm{n}=21)$ tinham o tecido íntegro.

Quanto ao exame da língua, o tamanho e a posição eram normais, porém $10 \%(\mathrm{n}=4)$ demonstravam coloração alterada e lesões, em $20 \%(n=8)$ dos casos foi constatada proeminência óssea devido ao uso de próteses em mau estado.

\section{DISCUSSÃO}

O estudo apontou a faixa etária de 71 a 75 anos como predominante, quanto ao estado civil, 29 (72\%) idosas eram solteiras e 10 (25\%) eram viúvas. A população brasileira atualmente apresenta um novo padrão demográfico que se caracteriza pela redução da taxa de crescimento populacional e por transformações profundas na composição de sua estrutura etária, com um significativo aumento do contingente de idosos, em sua maioria mulheres, com uma expectativa de vida média de 76,2 anos, ou seja, 7,6 anos a mais que os homens ${ }^{(16)}$.

Quanto à escolaridade, 31 idosas (77\%) não eram alfabetizadas. O alto índice de analfabetismo nessa faixa etária pode estar relacionado com a dificuldade de acesso ao ensino e falta de incentivo familiar para frequentar a escola, já que a maioria das mulheres era criada para que casassem e cuidassem do lar. Autores
Tabela 3 - Exame físico da cavidade oral de idosas em uma ILPI. Ponta Grossa, 2011

\begin{tabular}{lcc}
\hline Lábios & $\mathbf{n}$ & $\mathbf{\%}$ \\
Coloração normal & 37 & 93 \\
Coloração anormal & 3 & 7 \\
Presença de edema & 1 & 3 \\
Ausência edema & 39 & 97 \\
Hidratação & 35 & 88 \\
Desidratação & 5 & 12 \\
Total de lesões & 13 & 33 \\
Lesão lábio superior & 1 & 8 \\
Lesão lábio inferior & 9 & 69 \\
Lesão em ambos & 3 & 23 \\
Mucosa & $\mathbf{n}$ & $\mathbf{\%}$ \\
Coloração normal & 40 & 100 \\
Hidratação & 40 & 100 \\
Textura normal & 40 & 100 \\
Presença de lesão & 15 & 37 \\
Ausência de lesão & 25 & 63 \\
Gengiva & $\mathbf{n}$ & $\mathbf{\%}$ \\
Coloração normal & 40 & 100 \\
Presença de edema & 1 & 3 \\
Sangramento & 1 & 3 \\
Presença de lesão & 19 & 48 \\
Ausência de lesão & 21 & 52 \\
Língua & $\mathbf{n}$ & $\mathbf{\%}$ \\
Coloração & 4 & 10 \\
Tamanho & 40 & 100 \\
Posição & 40 & 100 \\
Presença de lesão & 4 & 10 \\
Palato & $\mathbf{n}$ & $\mathbf{\%}$ \\
Coloração normal & 40 & 100 \\
Formato normal & 40 & 100 \\
Proeminência óssea & 8 & 20 \\
\hline & & \\
& &
\end{tabular}

consideram que a escolaridade é uma variável importante, um fator de proteção à saúde, pois quanto mais instruído o indivíduo menor será a chance de exposição a fatores de risco para doenças e melhor será seu entendimento para autocuidado. . $^{(7,17)}$

Referente à necessidade de uso de prótese, observa-se um número significativo de idosas que utilizam, dado que converge com os resultados do Projeto Saúde Bucal Brasil 2010 que apontam mais de 3 milhões de brasileiros com 65 anos ou mais precisam de próteses completas e 4 milhões precisam de próteses parciais ${ }^{(17)}$. Portanto, o estado de conservação dentária dos idosos, a intensidade das doenças bucais e a prevalência de edentulismo são um reflexo do acesso à atenção em saúde bucal e da condição de vida desta população ${ }^{(18)}$. 
Em relação ao número de dentes, verificou-se $75 \%$ de edentadas. Os resultados encontrados podem ser explicados pelo fato de que os idosos na sua infância, podem não ter realizado os cuidados adequados com a higiene oral. Ressalta-se, que a perda dos dentes não é um fenômeno natural do envelhecimento, diversos motivos contribuem para a perda dentária e não está obrigatoriamente ligada à idade ${ }^{(19)}$. Estudos sobre necessidades de tratamentos odontológicos para pessoas idosas evidenciam que $55,74 \%$ delas sofrem de edentulismo, o que torna-se este um problema de saúde pública ${ }^{(20-21)}$.

As idosas dentadas, em sua maioria, apresentavam cáries, obturações e periodontites. A literatura nacional confirma essa realidade ao destacar que independentemente das condições de vida e saúde geral dos idosos, são altos os índices de edentulismo, cárie e doença periodontal, além da elevada necessidade de próteses $^{(4,22)}$.

Destaca-se ainda, que o uso de próteses pode aumentar a predisposição dos pacientes ao desenvolvimento de patologias, como a cárie dentária, periodontopatias e processos inflamatórios da mucosa, sendo a rotina de higiene oral essencial para manter a saúde dos tecidos, prevenindo o desenvolvimento das referidas patologias ${ }^{(23)}$.

Concernente à higiene oral, constatou-se uma situação precária e ruim. Por um lado, entende-se que com o avançar da idade, há uma tendência de declínio no nível de higiene bucal e aumento da incidência de doenças bucais. No entanto, fatores como a diminuição da capacidade motora, baixa autoestima, estímulo para a realização da higiene bucal, incapacidade de realizar sua própria higiene, comprometimento da visão e audição, contribuem para higiene bucal pobre e aumento do risco das pessoas idosas desenvolverem enfermidades bucais ${ }^{(24)}$.

O exame físico da cavidade oral apontou um número significativo de idosas $(\mathrm{n}=37 ; 93 \%)$ que apresentavam coloração de lábios normal. A hidratação labial pôde ser vista em $88 \%(n=35)$ das idosas. As lesões em lábios puderam ser observadas em $33 \%(n=13)$ residentes.

Em relação à mucosa $100 \%$ possuíam coloração, textura e hidratação normal, mas a incidência de lesões foi de $37 \%(n=15)$. Edema e sangramento foram observados em apenas $3 \%(n=1)$; a presença de lesão em tecido gengival foi observada em $48 \%(n=19)$ e $52 \%$ $(n=21)$ tinham o tecido íntegro.

Quanto ao exame da língua, o tamanho e a posição eram normais, porém $10 \%(\mathrm{n}=4)$ demonstravam coloração alterada e lesões, destaca-se que foi constatada em $20 \%(\mathrm{n}=8)$ das participantes, observou-se problemas bucais como líquen plano, hiperplasia e alteração da proeminência óssea, esta última podendo ser resultada do uso de próteses em mau estado.

A literatura aponta que as alterações gengivais mais comumente encontradas em pacientes idosos são diminuição da queratinização, aumento na largura da gengiva, diminuição da celularidade do tecido conjuntivo, aumento na quantidade de substâncias intercelulares, redução no consumo de oxigênio, retração e perda de inserção gengival ${ }^{(25)}$.

As hiperplasias fibrosas inflamatórias são as lesões que mais comumente aparecem em função, especialmente, da ação das bordas das dentaduras no fórnix dos vestíbulos. Elas representam uma resposta frente à compressão dos tecidos moles, formando grandes massas teciduais que, mesmo indolores, causam incômodo ao paciente ${ }^{(26)}$. Outro aspecto importante a ser ressaltado, é que o uso da escova de dente é um fator de risco para lesão de mucosa e gengiva de residentes edentadas.

\section{CONSIDERAÇÕES FINAIS}

Com o avançar da idade e a diminuição da cognição, há um aumento significativo na necessidade de auxílio em atividades cotidianas e a higienização da cavidade oral geralmente fica prejudicada. Dessa forma, pôde-se observar que o número de idosas dependentes é alto, e a necessidade total de cuidados torna-se um problema para a equipe cuidadora, dificultando o atendimento de qualidade prestado a cada uma delas.

Práticas de saúde preventivas são essenciais para evitar problemas bucais, nas quais devem ser adotadas técnicas e produtos diferenciados, adequados as necessidades dos idosos, exigindo conhecimento teórico e prático por parte de quem realiza a rotina de higienização. A avaliação da cavidade bucal é a primeira etapa para a elaboração de um protocolo de cuidado e deve ser realizada pela equipe de saúde, considerando a condição clínica, risco de sangramento, lesões na cavidade bucal, abertura da boca, presença ou não de dentes.

Destaca-se a importância do trabalho interdisciplinar, no qual os profissionais de saúde devem elaborar protocolos que possam ser exequíveis e promoverem treinamentos para adesão do tratamento, além de avaliarem, posteriormente, essas recomendações.

\section{REFERÊNCIAS}

1. Veras R. Envelhecimento populacional contemporâneo: demandas, desafios e inovações. Rev. Saúde Públ. [Internet] 2009;43(3) [acesso em 21 nov 2011]. Disponível: http://dx.doi.org/10.1590/S0034-89102009005000025 
2. Paulo MG, Teixeira AR, Jotz GP, Barba MC, Bergmann RS. Avaliação da qualidade de vida de cuidadores de idosos portadores de deficiência auditiva: influência do uso de próteses auditivas. Arq Int Otorrinolaringol. 2008;12(1):24-27.

3. Giacomin KC, Uchoa E, Lima-Costa MF. Projeto Bambuí: A experiência do cuidado domiciliário por esposas de idosos dependentes. Cad. Saúde Pública. 2005;21(5):1509-18.

4. Simões ACA, Carvalho DM. A realidade da saúde bucal do idoso no Sudeste brasileiro. Ciênc. saúde colet. 2011;16(6):2975-82.

5. Pereira MTP, Montenegro FLB. Idosos: prevenção na saúde bucal. Scribd [Internet] 2009 [acesso em ago 2011]. Disponível: http://pt.scribd.com/doc/17088229/ Idosos-prevencao-na-saude-bucal\#

6. Kawamura JY. Avaliação clínica, radiográfica e imunohistoquímica da doença periodontal em pacientes portadores de diabetes mellitus tipo 1 [dissertação]. São Paulo (SP): Universidade de São Paulo; 2002.

7. Araújo MVM, Vieira MA, Bonan PRF, Costa SM. Atuação dos profissionais de enfermagem nos cuidados com a higiene bucal de idosos institucionalizados em Montes Claros - MG. Rev APS. 2010;13(1):10-17.

8. Macentee MI. Missing links in oral health care for frail elderly people. J Can Dent Assoc. 2006;72(5):421-5.

9. MontalS, TraminiP, Triay JA, Valcarcel J. Oral hygiene and the need for treatment of the dependent institutionalized elderly. Gerodontology 2006;23(2): 67-72.

10. De Visschere L, Baat C, Schols JM, Deschepper E, Vanobbergen J. Evaluation of the implementation of na "oral hygiene protocol" in nursing homes: a 5-year longitudinal study. Community Dent Oral Epidemiol. 2011;39(5):416-25.

11. Saliba NA, Moimaz SAS, Marques JAM, Prado RL. Perfil de cuidadores de idosos e percepção sobre saúde bucal. Interface. 2007; 11(21):39-50.

12. Gonçalves LHT, Mello ALSF, Zimermann K. Validação de instrumento de avaliação das condições de saúde bucal de idosos institucionalizados. Esc. Anna Nery. 2010;14(4):839-47.

13. Bertolucci PHF. O miniexame do estado mental em uma população geral. Impacto da escolaridade. Arq. Neuropsiquiatria. 1994;52(1):1-7.
14. World Health Organization. Oral Health Surveys-Basic Methods. Geneva; 2007. p.36-9.

15. PintoVG. Saúde Bucal Coletiva. $6^{\mathrm{a}}$ ed. São Paulo: Santos; 2013.

16. Instituto Brasileiro de Geografia e Estatística-IBGE [Internet]. Rio de Janeiro. Indicadores sociodemográficos e de saúde no Brasil 2009 [acesso em 29 ago 2011]. Disponível: http://www.ibge.gov.br/home/estatistica/ populacao/indic_sociosaude/2009/default.htm

17. Saúde Bucal Brasil. Projeto Saúde Bucal Brasil 2010. [Internet] [acesso em 28 set 2011] Disponível: http:// www.sbbrasil2010.org/

18. Minas Gerais. Secretaria de Estado de Saúde. Atenção em Saúde Bucal. Belo Horizonte: SAS/MG; 2006.

19. Silva SO, Trentin MS, Linden MSS, Carli JP, Silveira Neto N, Luft LR. Saúde bucal do idoso institucionalizado em dois asilos de Passo Fundo - RS. RGO. 2008;56(3):303-8.

20. Tibério D, Santos MTBR, Ramos LR. Estado periodontal e necessidade de tratamento em idosos. Rev. Assoc. Paul. Cir. Dent. 2005;59(1): 69-72.

21. Silva SRC, Fernandes RAC. Autopercepção das condições de saúde bucal por idosos. Rev. Saúde Públ. 2001;35(4):349-55.

22. Colussi CF, Freitas SFT. Aspectos epidemiológicos da saúde bucal do idoso no Brasil. Cad. Saúde Pública. 2002;18(5):1313-20.

23. Fonseca $\mathrm{P}$, Areias $\mathrm{C}$, Figueiral MH. Higiene de próteses Removíveis. Rev Port Estomatol Cir Maxilofac. 2007;48(3):141-6.

24. Mello ALSF, Erdmann AL, Caetano JC. Saúde bucal do idoso: por uma política inclusiva. Texto Contexto Enferm. 2008;17(4):696-704.

25. Pereira MTP, Montenegro FLB. Terceira idade: a importância das lesões na mucosa bucal. [acesso em 28 out 2011] Disponível: http://boasaude.uol.com.br/ lib/emailorprint.cfm?id=5429\&type=lib.

26. Filho Gennari H. O exame clínico em prótese total. Revista Odontológica de Araçatuba. 2004;25(2):62-71. 